\title{
Spatial variation in avian bill size is associated with humidity in summer among Australian passerines
}

\author{
Janet L. Gardner ${ }^{1 *}$, Matthew R. E. Symonds ${ }^{2}$, Leo Joseph ${ }^{3}$, Karen Ikin ${ }^{4}$, John Stein ${ }^{4}$ and Loeske E. B. Kruuk ${ }^{1}$
}

\begin{abstract}
Background: Climate imposes multiple selection pressures on animal morphology. Allen's Rule proposes that geographic variation in the appendage size of endotherms, relative to body size, is linked to climatic variation, thereby facilitating heat exchange and body temperature regulation. Thus relatively larger appendages tend to be found in animals in warmer climates. Despite growing understanding of the role of the avian bill as an organ for heat exchange, few studies have tested the ecological significance of bill size for heat dissipation across species and environmental gradients. Amongst those that have, most have focused on the relationship with ambient temperature, but there is growing evidence that humidity also has a strong influence on heat dissipation. In particular, increasing humidity reduces the potential for evaporative cooling, favouring radiative and convective heat loss via the bill, and hence potentially favouring larger bills in humid environments. Here, we used phylogenetically-controlled analyses of the bill morphology of 36 species of Australian passerines to explore the relationship between bill size and multiple aspects of climate.

Results: Humidity during the hot summer months (December-February) was positively associated with relative bill surface area across species. There was no overall association between bill size and summer temperatures per se, but the association with humidity was mediated by temperature, with a significant interaction indicating stronger associations with humidity at cooler summer temperatures. This is consistent with the idea that larger bills may become disadvantageous in humid conditions as ambient temperature approaches body temperature. Relative bill size was similar among closely related species, with phylogeny explaining $63.3 \%$ of the variance, and there was significant variation among species in their response to humidity. However, the relationship between relative bill size and humidity was not associated with phylogeny.

Conclusions: Our results are consistent with the idea that body temperature regulation underlies continent-wide patterns of bill size variation in a broad range of Australian passerines, and suggests that Allen's Rule may apply to humidity gradients as well as temperature gradients. They add to growing evidence that a narrow focus on temperature alone in studies of responses to climate change may limit our understanding of species' sensitivities to climatic variation, and of their capacity to adapt.
\end{abstract}

Keywords: Meliphagoidea, Honeyeaters, Thermoregulation, Heat dissipation, Bill morphology, Bird beak, Allen's Rule, Climate, Humidity, Museum specimens

\footnotetext{
* Correspondence: janet.gardner@anu.edu.au

${ }^{1}$ Division of Evolution, Ecology and Genetics, The Australian National

University, Canberra, ACT 0200, Australia

Full list of author information is available at the end of the article
} 


\section{Background}

Morphology is important for thermoregulation in endotherms. In particular, variation in the size of and shape of morphological traits is linked to heat exchange and regulation of body temperature $[1,2]$. For example, smaller overall body size results in increased surface area to volume ratios, with improved capacity for heat dissipation, which may be advantageous in warmer climates [1]. This relationship between body size and heat exchange was originally proposed by [3] as an explanation for the observed geographical variation in endotherm body size that is associated with latitude and climate, an ecogeographic pattern known as Bergmann's Rule.

The avian bill is also fundamentally important for heat exchange and thermoregulation. Although bill morphology is strongly associated with diet and foraging niche $[4,5]$, there is also growing evidence of its significance in body temperature regulation [6-8] and heat exchange via the bill has been found in all species investigated to date [9]. The keratinized outer layer of the bill, the rhamphotheca, covers an extensive network of blood vessels into which blood may be pumped during exposure to high temperatures to achieve dissipation of excess metabolic heat via radiation and convection [10]. Thus, for example, the Toco toucan, Ramphastos toco can shunt up to $60 \%$ of its heat load through the bill when air temperatures exceed $28{ }^{\circ} \mathrm{C}$, reducing the need for evaporative cooling [6]. Southern yellow-billed hornbills, Tockus leucomelas, also use their bills as radiators to dump heat in hot conditions [9]. Heat loss via the bill can also be important in species with relatively small bills [11]; for example, although the bill of the song sparrow, Melospiza melodia, accounts for only about $2 \%$ of the bird's total surface area, it can shed up to $10 \%$ of the heat load [12]. Like Bergmann's Rule, Allen's Rule proposes that the pattern of geographic variation in the appendages of endotherms, relative to body size, will be linked to climatic variation [13]. It posits that larger appendages will be associated with warmer climates to facilitate heat dissipation. A comparative analysis of avian bill size across latitude in 214 species from 8 diverse groups provided strong support for Allen's Rule and the idea that thermoregulatory function has been a factor in the evolution of bird bills: larger bills were generally found in warmer climates [7].

In addition to information from studies of thermal physiology, there is also evidence that heat exchange may underlie intraspecific variation in bill size across species' distributions. For example, across the distribution of the song sparrow, a $17 \%$ increase in bill surface area was associated with ambient temperature increasing from 15 to $37{ }^{\circ} \mathrm{C}$, which led to a $33 \%$ improvement in the capacity to dissipate heat as indicated by thermal imaging [12]. Similarly, among 13 subspecies of the yellow warbler, Setophaga petechia, distributed throughout North and Central America, there was a strong positive relationship between bill size and ambient temperature in habitats experiencing mean maximum July (summer) temperatures in the range $18-41{ }^{\circ} \mathrm{C}[11]$. Larger bill size may be a particularly important adaptation in hot, arid environments where water availability is limited in summer $[9,12,14]$ since heat dissipation via the bill does not involve evaporative water loss, thereby improving water conservation [2, 15-17]. However, in extremely hot environments large bill size may be costly due to the risk of heat uptake. Where ambient temperatures regularly exceed body temperature the bill will absorb heat from the environment rather than dissipate it, so the advantages of large bill size may actually be reversed in extremely hot climates [18]. This suggests that there may be non-linear associations between temperature and optimal bill size. For instance, although relative bill size in song sparrows increased monotonically with ambient temperature across their range, bill size decreased in size in parts of their range where average summer temperatures exceeded body temperature, above about $36^{\circ} \mathrm{C}$ [14].

To date most studies of the role of bill size in heat exchange have focused on the relationship with ambient temperature and/or aridity, but there is growing evidence that humidity also has a strong influence on heat dissipation. Aridity is determined by levels of rainfall, which may vary independently from humidity, i.e. atmospheric water vapour pressure. For most birds the primary means of dissipating heat is via evaporative cooling from cutaneous and respiratory surfaces $[2,16]$. However, high humidity reduces the gradient driving evaporation thereby reducing the rate of heat loss via evaporative cooling $[2,16]$. In such conditions, birds may rely on heat loss from the bill via radiation and convection, the efficiency of which is unaffected by humidity (Andrew McKechnie and Blair Wolf, pers comm). This suggests adaptive advantages of larger bill sizes in hot, humid conditions [9, 12, 19-21]. Allen's rule may therefore apply to humidity gradients as well as temperature gradients: large appendages should be particularly advantageous to birds inhabiting hot climates that are also humid [9, 12].

Despite growing understanding of the role of the avian bill in heat exchange, there have been very few studies testing the ecological significance of bill size for heat dissipation across species and environmental gradients. Australian passerines provide a useful model in this regard because the continent comprises a diverse range of climatic regions, including arid (desert) and humid (tropical) regions that experience high summer temperatures. Accordingly, selection pressures acting on traits linked to heat exchange are expected to be strong. Here, using a phylogenetically-controlled comparative analysis 
and bill morphology data from museum collections of 36 species of Australian passerines, we test two nonmutually exclusive hypotheses regarding variation in avian bill size and associated heat-related mechanisms. We use measures of summer weather in order to explore associations with climate at times when temperatures will be at their highest. We test the following predictions:

(1)Larger relative bill size should be associated with warmer climates, in accordance with Allen's Rule [13]. However, in hot climates where ambient temperature regularly exceeds body temperature, the selection pressure acting on bill size may be reversed in favour of smaller bills in regions experiencing very hot summer temperatures. We therefore predict a non-linear association with temperature.

(2)Larger relative bill size will be associated with climates where hot conditions coincide with high humidity, because increasing humidity reduces the potential for evaporative cooling, favouring heat transfer via the bill.

\section{Methods}

\section{Study species}

Our study focused on 36 species of Australian passerine from the Meliphagoidea (honeyeaters and allies), a large and diverse group of Australasian passerines that is widely distributed across habitats and climatic regions and for which robust, species-level molecular phylogenies are available $[22,23]$. The species in our study ranged from 6 to $101 \mathrm{~g}$ (mean female body mass), included both insectivores and nectarivores and sedentary and mobile species, and occupied a diversity of climatic regions (Table 1) [22, 23].

We measured the bills of 2,864 adult individuals using museum specimens collected across the geographic ranges of each species between 1970 and 2012 (Table 1, Fig. 1, Additional file 1: Figure S1). The specimens we examined are housed at the Australian National Wildlife Collection at CSIRO in Canberra, the Australian Museum in Sydney and Museum Victoria in Melbourne, Australia. We recorded the sex and year of collection of each specimen and location (latitude, longitude) and biogeographic region in which each specimen was collected. Biogeographic region was based on the Interim Biogeographic Regionalisation for Australia (IBRA version 6), with specimens from 77 biogeographic regions included in our study. We excluded juveniles and subadults identified by information provided in museum metadata or from age-related differences in plumage. We restricted our sampling to birds collected prior to 2012 to eliminate the confounding effect of shrinkage, which occur in the first few years after preservation [24].

\section{Morphometric measurements}

We measured bill length (BL), width (BW) and depth (BD) of the exposed bill for each individual using digital calipers with direct download to a spreadsheet to reduce transcription errors. Bill length was measured from the feathering at base of the upper mandible (maxilla) to the bill tip, bill width from the posterior edge of the nares (nostrils) on one side of the bill to the same on the other side, and bill depth from the posterior edge of the nares on the upper mandible to the bottom of the lower mandible at right angles to the tomia, i.e. the cutting edge of the bill. Bill measurements were converted to an estimate of the surface area of the bill using the formula $((\mathrm{BW}+\mathrm{BD}) / 4) \times \mathrm{BL} \times \pi$, which approximates lateral surface area of a nearly circular elliptical cone [14]. To estimate bill size relative to overall body size, we used an index of body size measured as the length of the flattened wing chord from the carpal joint to the tip of the longest primary (wing length is the best single linear predictor of structural body size [25]; see Additional file 1: Figure S2 for relative bill surface area of each species. Because feathers abrade over the course of the year, between successive moults, and can affect wing length, we accounted for feather wear in our estimate of wing length using the residuals from a regression between wing length and an 'abrasion score' [26]. All measurements were undertaken by the same person (Jesse Smith).

\section{Climate data}

We estimated climate variables at all collection locations of each species. These point data were interpolated from the ANUClimate 1.0 spatial model of monthly Australian climate variables on a $0.01^{\circ}$ longitude/latitude grid for the period January 1970 to December 2013 [27]. For the 72 months preceding each collection date, we collated monthly estimates of mean maximum temperature, total rainfall $(\mathrm{mm})$, and mean humidity (water vapour pressure in hectopascals); these being derived from daily records. From these data we calculated mean maximum temperature, mean total rainfall and mean water vapour pressure (WVP) for the austral summer, by averaging the values for the months December, January and February. Individuals were captured at all months throughout the year, so we calculated climate variables for the last summer experienced by each individual prior to capture, as well as the preceding 4 summers, and averaged to give estimates of climate over the previous 5 years. Correlations amongst the three explanatory climate variables are shown in Additional file 1: Table S1 and Figure S3.

\section{Statistical analyses}

We used a spatially-explicit, phylogenetically controlled comparative analysis to analyse the data. We wished to explore variation in relative bill size, i.e. accounting for 
Table 1 Sample sizes, mean wing length $(\mathrm{mm})$ and female body mass for each species included in the study

\begin{tabular}{|c|c|c|c|c|}
\hline Species & Common Name & Number of Individuals & Mean Wing Length (mm) & Mean Female Mass (g) \\
\hline \multicolumn{5}{|l|}{ Maluridae } \\
\hline Malurus cyaneus & Superb Fairy-wren & 39 & 50.13 & 9.6 \\
\hline Malurus lamberti & Variegated Fairy-wren & 99 & 47.63 & 8.1 \\
\hline Malurus leucopterus & White-winged Fairy-wren & 77 & 46.65 & 7.3 \\
\hline Malurus melanocephalus & Red-backed Fairy-wren & 72 & 42.69 & 7.5 \\
\hline \multicolumn{5}{|l|}{ Acanthizidae } \\
\hline Acanthiza apicalis & Inland Thornbill & 113 & 51.84 & 6.9 \\
\hline Acanthiza lineata & Striated Thornbill & 170 & 52.16 & 7.2 \\
\hline Acanthiza nana & Yellow Thornbill & 82 & 49.52 & 6.3 \\
\hline Acanthiza pusilla & Brown Thornbill & 105 & 51.00 & 6.9 \\
\hline Acanthiza reguloides & Buff-rumped Thornbill & 65 & 52.84 & 7.2 \\
\hline Acanthiza uropygialis & Chestnut-rumped Thornbill & 100 & 50.69 & 6.2 \\
\hline Aphelocephala leucopsis & Southern Whiteface & 121 & 58.53 & 12.4 \\
\hline Sericornis frontalis & White-browed Scrubwren & 85 & 55.88 & 12.5 \\
\hline Sericornis magnirostris & Large-billed Scrubwren & 90 & 56.20 & 9.3 \\
\hline Smicrornis brevirostris & Weebill & 65 & 49.63 & 5.8 \\
\hline \multicolumn{5}{|l|}{ Meliphagidae } \\
\hline Acanthorhynchus tenuirostris & Eastern spinebill & 31 & 65.90 & 10 \\
\hline Acanthagenys rufogularis & Spiny-cheeked Honeyeater & 102 & 111.13 & 42.8 \\
\hline Anthochaera carunculata & Red Wattlebird & 41 & 151.91 & 101.1 \\
\hline Conopophila rufogularis & Rufous-throated Honeyeater & 46 & 71.16 & 10.6 \\
\hline Entomyzon cyanotis & Blue-faced Honeyeater & 97 & 146.91 & 97.4 \\
\hline Epthianura tricolor & Crimson Chat & 38 & 66.92 & 10.7 \\
\hline Gavicalis virescens & Singing Honeyeater & 79 & 89.28 & 23.9 \\
\hline Lichenostomus melanops & Yellow-tufted Honeyeater & 99 & 85.81 & 24.5 \\
\hline Lichmera indistincta & Brown Honeyeater & 95 & 65.82 & 9.3 \\
\hline Manorina flavigula & Yellow-throated Miner & 100 & 124.84 & 55.8 \\
\hline Manorina melanocephala & Noisy Miner & 64 & 137.16 & 57.9 \\
\hline Meliphaga lewinii & Lewin's Honeyeater & 86 & 98.56 & 31.9 \\
\hline Melithreptus albogularis & White-throated Honeyeater & 81 & 70.93 & 11 \\
\hline Myzomela obscura & Dusky Honeyeater & 51 & 67.47 & 10.7 \\
\hline Nesoptilotis leucotis & White-eared Honeyeater & 49 & 91.13 & 20.1 \\
\hline Phylidonyris novaehollandiae & New Holland Honeyeater & 83 & 76.07 & 19.2 \\
\hline Phylidonyris pyrrhoptera & Crescent Honeyeater & 67 & 72.69 & 13.9 \\
\hline Ptilotula penicillata & White-plumed Honeyeater & 130 & 80.08 & 17.3 \\
\hline Ptilotula plumula & Grey-fronted Honeyeater & 67 & 76.29 & 16.8 \\
\hline Stomiopera unicolor & White-gaped Honeyeater & 43 & 95.33 & 29.1 \\
\hline \multicolumn{5}{|l|}{ Pardalotidae } \\
\hline Pardalotus punctatus & Spotted Pardalote & 72 & 57.20 & 8.4 \\
\hline Pardalotus striatus & Striated Pardalote & 60 & 64.79 & 11.3 \\
\hline
\end{tabular}

We report female body mass from [52], and mean wing length calculated from individuals included in the study

body size, so in all models we fitted wing length as a covariate to first correct for overall variation in body size. We tested for the effects of climate on bill surface area (hereafter bill size) by fitting bill size as a response variable and climate variables as predictors. All models also controlled for sex, year and season of collection. Season 


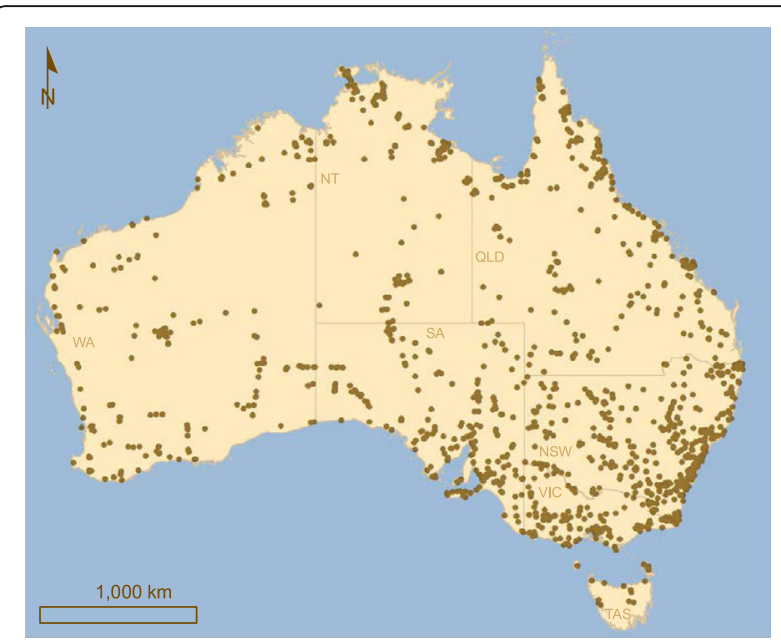

Fig. 1 Locations at which museum specimens were sampled. See Additional file 1: Figure S1 for locations at which museum specimens were sampled, in relation to the distribution of each species

(spring, summer, autumn, winter) was included because the rhamphotheca (see Background) grows and wears continuously and rates of wear vary with seasonal changes in diet, and also because bills are used as a sexual signal in some species and may therefore change dimensions prior to the breeding season [28]. Because specimens included in our study were collected over a 42-year period, during which time the climate has been changing rapidly, we controlled for temporal changes in climate by including year of collection as a covariate; this allowed us to focus on spatial, not temporal, associations between bill size and climate.

The data were analysed using a mixed model fitted in the package ASReml [29]. Bill surface area was logtransformed to ensure normality of residuals. In addition to the climate variables, all models contained the fixed effects as described above: wing length, sex, season, and year as a continuous variable. All models also contained random effects of IBRA region (defined above, to account for morphological similarities among individuals from the same geographic regions), year (as a multi-level factor, to account for the repeated measures on each year; note that this is necessary to avoid pseudoreplication when testing both for the effects of climatic variation and for the temporal trend with year as a covariate), and species (to account for sampling of multiple individuals within a species). This mixed model framework allowed us to further probe the role of the phylogeny in shaping differences between species, differences in their response to climatic variation, and any potential interaction between the two. We did so by comparing a series of four models with increasingly complex random effects structure.
Our first model (Model 1) contained just the random effects described above. Thus for observation $\mathrm{y}_{\mathrm{i}}$ on bird $\mathrm{i}$, the model was of the form:

$$
y_{i}={\text { fixed effects }+ \text { region }_{i}+\text { year }_{i}+\text { species }_{i}+\text { res }_{i}(\text { model } 1),}
$$

where terms in italics indicate random effects. The full version of model 1 contained fixed effects of all three weather variables (Tmax, Rain and WVP), their quadratic terms and all three pairwise interactions. As we show in the Results, we found significant effects of summer humidity (water vapour pressure) and its interaction with temperature across all species, so all subsequent models contained just Tmax, WVP and their interaction as climate variables. In this model, the total phenotypic variation $V_{P}$ in relative bill size (after correcting for fixed effects) was thus decomposed into components of variance due to region, year, species and residual effects respectively.

We then incorporated phylogenetic information to estimate the extent to which differences between species were phylogenetically-determined. We constructed a phylogeny for the 36 species which was derived using information from the "Global Phylogeny of Birds" website - www.birdtree.org [30]. Specifically, we downloaded 2000 trees for the 36 species from the pseudo-posterior distribution of trees using the [31] backbone. We then used these 2000 trees to calculate a majority-rule consensus phylogeny which was used as the basis for analysis. We resolved polytomies in the consensus phylogeny using a recently published phylogeny for the Meliphagidae [23]. We scaled the branch lengths observed in Meliphagidae [23] to that of the consensus phylogeny. The scaling was based on the distance from the base of the Meliphagidae to the species with the longest evolutionary branch length leading to it (Myzomela obscura). We used this distance (31.85) as the basis for rescaling all the other branch lengths. The tree was made ultrametric using the compute. brlen package from the $R$ package ape [32]. We then added the phylogenetic component [33], using the inverseA and sm2asreml functions from the $\mathrm{R}$ package MCMCglmm [34] to invert the phylogenetic covariance matrix for inclusion in the ASReml model. This model (model 2) still also included a term to account for differences between species not due to phylogeny (see e.g. [35]), thus partitioning the variance as:

$$
\begin{aligned}
& y_{i}=\text { fixed }+ \text { region }_{i}+\text { year }_{i}+\text { species.phylo } \\
& \text { phylo }_{i}+\text { ses }_{i}(\text { model } 2),
\end{aligned}
$$

We then (model 3) tested for differences between species in their response to climate by incorporating a 
random regression component to the model (see for example [36]). Because humidity had the clearest main effect, we modelled random slopes for each species' response to humidity (WVP) by inclusion of an interaction between WVP and species (though without linking the interaction to the phylogeny):

$$
\begin{aligned}
& y_{i}=\text { fixed }+ \text { region }_{i}+\text { year }_{i}+\text { sp.phylo } \\
& \text { W }
\end{aligned}
$$

This model also included a term for the covariance between random intercepts and slopes for humidity.

Finally (model 4), we tested for a phylogenetic component to the differences between species in their response to humidity:

$$
\begin{aligned}
& y_{i}=\text { fixed } \text { region }_{i}+\text { year }_{i}+\text { sp.phylo } \\
& \text { WVP:sp.non-phylo } \\
& \text { WVylo }
\end{aligned}
$$

We compared each of these models with the previous one using likelihood ratio tests (on 1 d.f. for the comparison between model 1 and 2, and 2 d.f. for the subsequent comparisons involving models 3 and 4, as in each case we had added two parameters: a variance and a covariance component).

\section{Results}

\section{Effects of maximum summer temperature and rainfall}

We found no evidence for any direct linear or nonlinear association between bill size and maximum summer temperature, with neither the main effect nor the quadratic term for summer maximum temperature being significant (Table 2). Similarly, we also found no evidence for any associations with rainfall, with neither

\begin{tabular}{|c|c|c|c|c|c|}
\hline & Wald statistic & Df & $p$-value & parameter & SE \\
\hline (Intercept) & 2354.543 & 1 & $<0.001$ & 5.768 & 0.559 \\
\hline Wing Length & 656.986 & 1 & $<0.001$ & 0.01145 & 0.00056 \\
\hline SeasonCapture.autumn & 49.425 & 3 & $<0.001$ & 0 & NA \\
\hline winter & & & & -0.00958 & 0.00543 \\
\hline summer & & & & 0.03092 & 0.00758 \\
\hline spring & & & & 0.01419 & 0.00543 \\
\hline Sex.female & 59.914 & 1 & $<0.001$ & 0 & NA \\
\hline male & & & & 0.02894 & 0.00423 \\
\hline YearCapture & 10.097 & 1 & 0.001 & -0.00089 & 0.00027 \\
\hline Humidity & 66.511 & 1 & $<0.001$ & 0.01802 & 0.00765 \\
\hline Tmax & 0.514 & 1 & 0.473 & 0.00386 & 0.00743 \\
\hline Rain & 0.668 & 1 & 0.414 & -0.00058 & 0.00042 \\
\hline Humidity $^{2}$ & 0.435 & 1 & 0.510 & 0.00048 & 0.0002 \\
\hline $\operatorname{Tmax}^{2}$ & 0.414 & 1 & 0.520 & 0.00012 & 0.00014 \\
\hline Rain $^{2}$ & 0.239 & 1 & 0.625 & $6.28 \mathrm{E}-07$ & $5.41 \mathrm{E}-07$ \\
\hline Humidity * Tmax & 4.284 & 1 & 0.038 & -0.00085 & 0.00027 \\
\hline Humidity* Rain & 0.491 & 1 & 0.483 & -0.00004 & 0.00002 \\
\hline Tmax * Rain & 5.250 & 1 & 0.022 & 0.00004 & 0.00002 \\
\hline Variance of random effects & Component & SE & & & \\
\hline Region & 0.000502 & 0.000158 & & & \\
\hline YearCapture & 0.000163 & 0.0000821 & & & \\
\hline Species & 0.1485 & 0.0360 & & & \\
\hline Residual & 0.008474 & 0.000230 & & & \\
\hline
\end{tabular}
the main effect nor the quadratic term for rainfall being significant (Table 2).

Table 2 Factors affecting bill surface area of 36 species of passerine from the Meliphagoidea

Results are from a full mixed model of bill size (log-transformed) with fixed effects of body size (wing length), season of capture, sex and all weather variables and their interactions and quadratic terms, and random effects of species, IBRA region, year and residual effect (see Model 1 in Methods). The table shows Wald statistics, df, p-values, parameter estimates and standard errors (SE). Tmax is the mean maximum summer temperature; humidity is mean summer water vapour pressure $(\mathrm{hPa})$, and rainfall is mean summer rainfall, all averaged for the preceding 5 summers prior to capture; summer is defined as the months December to February. Parameter estimates for Season of Capture are relative to autumn, and for Sex are for males relative to females. Log-likelihood of model $=5102.48$. $N=2864$ individuals, across 41 years, 36 species and 77 IBRA regions. Significant weather terms $(p<0.05)$ are shown in bold 


\section{Effects of humidity}

Bill size was strongly associated with humidity (water vapour pressure) showing significant increases on average across the species (Table 2; Fig. 2). The correlation between relative bill size and humidity was 0.38 , corresponding to an $R^{2}$ of 0.14 . However, the association between bill size and humidity differed with maximum summer temperature (humidity x Tmax interaction; Table 2, Fig. 3, Additional file 1: Figure S4). There was also a significant interaction between Tmax and rainfall (Table 2, $p=0.021$ ) in the initial full model. However, this interaction was no longer significant once we had dropped other nonsignificant terms from the model, nor was it significant in any subsequent models (2-4), and so we did not include it in any further models.

\section{Effects of phylogeny and species variation in response to climate}

Table 3 shows a comparison of the four models with increasing complexity of random effects structure. Including covariance between species due to phylogeny resulted in a significant improvement to the model (Table 3, Model 2 vs $1 ; p<0.001)$ : differences between species in relative bill size had a strong phylogenetic component. There was also a significant increase in log-likelihood on adding a random effect to allow the effect of humidity to vary between species (i.e. random slopes for humidity: Model 3 vs $2, p<0.001$, Table 3 ). However, there was no indication that this variation between species in response to humidity had a phylogenetic basis, i.e. there was no improvement on adding an interaction between humidity and the effect of species relatedness

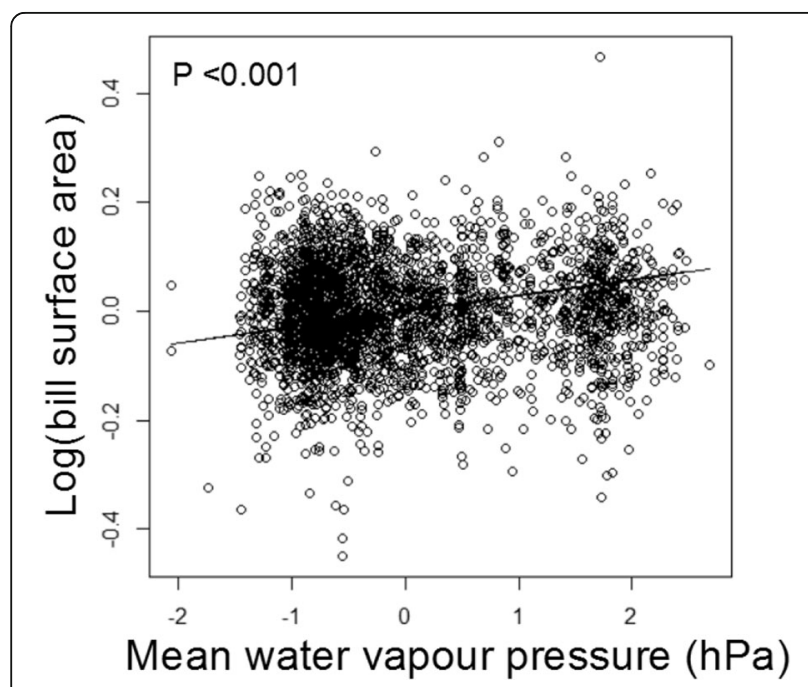

Fig. 2 The association between bill surface area (log-transformed) and humidity for 36 species passerine from the Meliphagoidea $(n=2867$ individuals). Humidity is mean summer water vapour pressure (hPa) averaged for the preceding 5 summers prior to capture; summer is defined as the months December to February

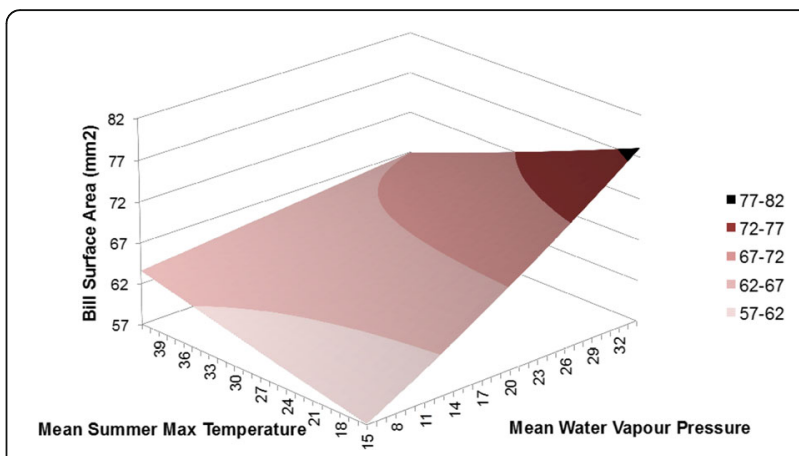

Fig. 3 The interaction between humidity and maximum temperature influencing bill surface area for 36 species passerine from the Meliphagoidea ( $n=2867$ individuals). Humidity is mean summer water vapour pressure $(\mathrm{hPa})$ and temperature is mean maximum summer temperature averaged for the preceding 5 summers prior to capture; summer is defined as the months December to February. Colours represent categories of bill surface area

via the phylogeny (Model 4 vs 3 ). The full output of the best model (Model 3) is shown in Table 4.

\section{Discussion}

Of the climatic variables we have considered, humidity most strongly predicted relative bill size across the ranges of 36 ecologically diverse species of Australian passerine bird. Humidity during the summer months (December, January, February) when temperatures are high was positively associated with relative bill surface area, with bill size increasing with increasing humidity across species (Fig. 2). However, the strength of the association between bill size and humidity was mediated by maximum summer temperature, with a significant interaction indicating slightly stronger associations with humidity at cooler summer temperatures (Fig. 3). Relative bill size also showed a strong phylogenetic signal, with the random effect associated with phylogeny explaining $63.3 \%(18.4 \% \mathrm{SE})$ of the variance remaining after accounting for fixed effects (Table 4). There was also significant variation between species in their association between relative bill size and humidity. However, despite the strong phylogenetic effect on average bill size, the relationship between bill size and humidity was not associated with the phylogeny, indicating that bill size variation associated with humidity is more likely to be environmentally determined.

Our results suggest that bill size may be important for heat dissipation at high humidity during summer, when temperatures are high, and hence that Allen's Rule may apply to humidity as well as temperature gradients. Our results especially relate to tropical environments in Australia because conditions of sustained high humidity do not coincide with high summer temperatures in other Australian climatic zones. At high humidity, radiative and convective, rather than evaporative, cooling may be 
Table 3 Comparison of models of (log) bill size with increasing complexity of random effects structure, to test for effects of phylogeny and of variance between species in the slope of their response to humidity; see Methods for details of models

\begin{tabular}{|c|c|c|c|c|c|}
\hline Model & Variance components & $\log \mathrm{L}$ & $x^{2}$ & d.f. & $p$-value \\
\hline 1 & $V_{\text {region }}+V_{\text {year }}+V_{\text {species }}+V_{\text {res }}$ & 5163.20 & & & \\
\hline 2 & $V_{\text {region }}+V_{\text {year }}+V_{\text {sp.non-phylo }}+V_{\text {sp.phylo }}+V_{\text {res }}$ & 5179.149 & 19.83 & 1 & $<0.001$ \\
\hline 3 & $V_{\text {region }}+V_{\text {year }}+V_{\text {sp.non-phylo }}+V_{\text {sp.phylo }}+\left(V_{\text {sp.non-phylo }} x\right.$ humidity $)+V_{\text {res }}$ & 5183.95 & 23.36 & 2 & $<0.001$ \\
\hline 4 & $V_{\text {region }}+V_{\text {year }}+V_{\text {sp.non-phylo }}+V_{\text {sp.phylo }}+\left(V_{\text {sp.non-phylo }} x\right.$ humidity $)+\left(V_{\text {sp.phylo }} x\right.$ humidity $)+V_{\text {res }}$ & 5183.95 & 0.00 & 2 & 1.00 \\
\hline
\end{tabular}

All models included fixed effects of wing length (to correct for body size), sex, season, year of capture, humidity, Tmax, and the interaction between humidity and Tmax. LogL gives the log-likelihood of each model; $X^{2}$ is the likelihood ratio test for comparison with the previous model, with corresponding degrees of freedom (d.f.): models 3 and 4 each required an additional 2 d.f. because they estimated one additional parameter for variance in slopes and and one for covariance between intercept in slope (see Methods). The best model (Model 3 ) is shown in bold. Definitions of terms: $V_{\text {region }}$ IBRA region, $V_{\text {year }}$ year, $V_{\text {sp.non-phylo }}$ variance between species not associated with phylogeny, $V_{\text {sp.phylo }}$ variance between species associated with the phylogeny, $V_{\text {sp.non-phylo }} X$ humidity variance in humidity-slope not associated with phylogeny, $V_{\text {sp.phylo }} X$ humidity variance in humidity-slope associated with phylogeny, $V_{\text {res }}$ residual variance

a more effective means of heat dissipation because the gradient driving evaporation is reduced by humidity. Thus, selection on relative bill size is predicted to be particularly strong in these conditions [20]. Gerson and colleagues [20] found that high humidity inhibited rates of evaporative water loss by up to $36 \%$ at $48{ }^{\circ} \mathrm{C}$, in sociable weavers, Philetairus socius, in a desert environment that experienced discrete rainfall events that resulted in prolonged periods of high humidity. Work on Anna's hummingbird, Calypte anna, [37] also suggests that humidity reduces the effectiveness of evaporative cooling but at much lower temperatures, between 20 and $37{ }^{\circ} \mathrm{C}$ [20], which largely overlaps the temperature range included in our study. In humid conditions, heat transfer via the bill via radiative or convective cooling may compensate for the inefficiency of evaporative cooling. Such compensation may be beneficial given that reductions in the efficiency of heat dissipation during panting may compromise survival during extended periods of exposure to high temperatures in humid conditions [20].

Table 4 Full output of Model 3: best model of factors affecting bill surface area

\begin{tabular}{|c|c|c|c|c|c|}
\hline & Wald statistic & Df & $p$-value & parameter & SE \\
\hline (Intercept) & 500.722 & 1 & $<0.001$ & 5.650 & 0.56786 \\
\hline Wing length & 636.932 & 1 & $<0.001$ & 0.011 & 0.000568 \\
\hline SeasonCapture.autumn & 51.499 & 3 & $<0.001$ & . & . \\
\hline winter & & & & -0.010 & 0.005387 \\
\hline summer & & & & 0.031 & 0.007547 \\
\hline spring & & & & 0.013 & 0.005351 \\
\hline Sex (male relative to female) & 60.443 & 1 & $<0.001$ & 0.031 & 0.004217 \\
\hline YearCapture (continuous) & 11.150 & 1 & 0.001 & -0.00091 & 0.00027 \\
\hline Humidity & 26.335 & 1 & $<0.001$ & 0.0160 & 0.00544 \\
\hline Tmax & 0.338 & 1 & 0.561 & 0.00587 & 0.00274 \\
\hline Humidity.Tmax & 4.277 & 1 & 0.039 & -0.0003467 & 0.000168 \\
\hline Variance/covariance of random effects & Component & SE & & & \\
\hline Region & 0.000446 & 0.000142 & & & \\
\hline YearCapture & 0.000166 & 0.000082 & & & \\
\hline Species:Phylo & 0.108706 & 0.070089 & & & \\
\hline Species:NonPhylo & 0.053945 & 0.017836 & & & \\
\hline cov(SpeciesNonPhylo,SpNonPhylo:Humidity) & 0.001227 & 0.001389 & & & \\
\hline SpNonPhylo:Humidity & 0.000480 & 0.000211 & & & \\
\hline Residual & 0.008343 & 0.000227 & & & \\
\hline
\end{tabular}

Results are from a full mixed model of bill size (log-transformed) with fixed effects of body size (wing length), season of capture, sex, humidity, Tmax and the interaction between humidity and Tmax. The table shows Wald statistics, df, p-values, parameter estimates and standard errors (SE). Significant weather terms $(p<0.05)$ are shown in bold. The random effects were region, year of capture (multi-level factor), phylogenetic species effect (SpeciesPhylo), a non-phylogenetic species effect (SpeciesNonPhylo), and an effect of humidity for each species (not linked to the phylogeny; SpNonPhylo:Humidity); see further details of Model 3 in Methods. The table shows the variance components for each random effect (and SE), and also the covariance between the intercepts and slope for the non-phylogenetic species effect, which was also fitted. Parameter estimates for Season of Capture are relative to autumn, and for Sex are for males relative to females. $N=2864$ individuals; 36 species; 41 years; 77 IBRA Regions. Log-likelihood of model = 5187.482 
This suggests there will be strong selection for larger bills in humid environments, consistent with our findings and prediction (2) above. Given the diverse range of species included in this study, reliance on the bill for cooling in humid summer conditions may be a common strategy in Australian birds.

Bird bills may no longer be effective in dissipating heat when air temperatures exceed body temperature because bills become a source of heat gain, drawing heat into the body rather than dissipating it $[9,12]$. Our results show that the strength of the association between bill size and humidity was mediated by maximum summer temperature, with stronger associations with humidity at cooler summer temperatures. When air temperature exceeds body temperature (ca. $40{ }^{\circ} \mathrm{C}$ for birds), the only avenue available for heat dissipation is evaporation [2,38], and larger bills in these conditions may provide no adaptive advantage, and indeed may become detrimental to survival.

The effects of humidity on heat dissipation have been litthe studied in tropical environments [20,39], despite the fact that birds and mammals are already thought to be highly sensitive to climate change in these regions [40-43]. Recent studies suggest that tropical endotherms have limited physiological safety margins, and that small-bodied species may be at particular risk of climate change [44-46]. Our study suggests that constraints imposed by humidity on heat dissipation may be widespread among passerine species and contribute to the thermal sensitivities of birds in the tropics. Small passerines have high levels of metabolic heat production and tend to rely on evaporative cooling, so may be particularly sensitive to changes in climate in the tropics $[37,47]$. The reduced effectiveness of evaporative cooling in high humidity, together with temperature-dependent costs on the function of heat loss via the bill when air temperatures exceed body temperature, suggests a narrow thermal window for temperature regulation. As temperatures rise and rainfall patterns shift, this thermal window may narrow, with potential for fitness consequences for tropical birds. Data from field studies of thermoregulation in tropical endotherms are thus currently needed to clarify these issues.

Our analysis also suggests a significant temporal trend in relative bill surface area over the 1970-2012 period during which the specimens were collected. Although this finding provides further evidence of changes in the size and shape of endotherm appendages concurrent with ongoing climate change, as recently demonstrated in the bill sizes of some Australian parrots [21], the trend is in the opposite direction (relatively smaller bills over time). However we note that the effect size was minimal $\left(-0.00091 \mathrm{~mm}^{2}\right.$ per year), and equates to a decrease of only $0.27 \%$ over the 50 -year study period, which is unlikely to be biologically meaningful.
Surprisingly, we found no evidence for a positive association between bill size and temperature per se as is predicted by Allen's Rule, which suggests that species in our study use alternative strategies for dissipating heat in summer when ambient temperatures are high. For many birds, evaporative cooling via cutaneous and respiratory tissues is the primary means of dissipating heat, and can be more efficient than radiative and convective heat loss via the bill [48]. Heat loss may also be achieved through non-evaporative heat dissipation through the legs, and Allen's Rule predicts increases in leg size in relation to temperature [12, 14]. Behavioural thermoregulation may also allow species to avoid exposure to hot conditions [49]. Birds in our study may have used these strategies to cope with increasing heatloads associated with higher temperatures, but we lack the data to assess them. Additionally, it may be that bill surface area is more closely associated with minimum winter temperature, rather than maximum summer temperature, which would suggest that selection primarily acts on bills to be smaller in colder conditions in order to aid winter heat retention, rather than on bills to be larger when it is hot to aid summer heat dissipation. Symonds \& Tattersall [7] found evidence that smaller bill sizes were most closely associated with minimum winter temperatures in the species they examined, which may be related to issues of heat conservation, but this is outside the scope of this study. Danner \& Greenberg [50] have also demonstrated that different populations of song sparrows exhibit different 'critical seasons' in terms of the relationship between bill size and temperature: Californian populations show an Allen's rule pattern in relation to maximum summer temperature, but midAtlantic populations do not, and only exhibit the same pattern in relation to minimum winter temperature.

The arguments above indicate that there are many aspects of thermoregulation in wild animal populations yet to be fully understood. It is also worth considering the actual mechanisms that may have driven the associations shown here between climate and morphology none of them exclusive. While the patterns may be adaptive evolutionary responses to selection shaped by local climatic conditions, thermoregulatory selection pressures may also have changed the distribution of phenotypes within a generation, regardless of whether those changes generate genetic change. The pattern could also be driven by developmental phenotypic plasticity if individuals experiencing humid conditions during summer grow relatively larger bills. Finally, any of these responses could potentially be driven by other mechanisms, such as an impact of relative bill size on foraging ability or diet (for example, if humid conditions result in changes in primary productivity such that seed size, for example, is larger in tropical warm environments; [51]). However, 
we cannot distinguish these different scenarios with the current data: further work is needed to explore possible explanations for the observed patterns.

\section{Conclusions}

Our study demonstrates the ongoing value of museum collections in providing insights into spatial and temporal trends within and across species; only such collections can provide the necessary time series for testing the ecological significance of traits at this scale. Our results provide evidence that Allen's Rule applies to humidity gradients, and are consistent with the idea that body temperature regulation underlies continent-wide patterns of bill size variation in a broad range of Australian passerines. We demonstrate that humidity has a much stronger association with bill size than does temperature per se, but temperature mediates the association between humidity and bill size, suggesting shifts between reliance on evaporative versus radiative and convective cooling are associated with different climatic regimes, as suggested by studies of thermal physiology [9]. In combination with our finding for environmental determination of the species-level association between humidity and bill size, our results suggest that responses to contemporary change in climate will vary among populations of the same species. Our results support those of others who have emphasized the role of multiple environmental factors in shaping the evolution of bill morphology [8]. They also add to growing evidence that a narrow focus on temperature alone in studies of responses to climate change is overly simplistic and limits our understanding of species' sensitivities to climate change, and their capacity to adapt.

\section{Additional file}

Additional file 1: Table S1. Correlations among explanatory variables included in models. Tmax is the mean maximum summer temperature; humidity is mean summer water vapour pressure $(\mathrm{hPa})$, and rainfall is mean summer rainfall averaged for the preceding 5 summers prior to capture; for all variables, summer is defined as the months December to February. Figure S1 Locations at which museum specimens were sampled (points), in relation to the distribution of each species, shown in dark brown. Figure S2 Boxplot showing relative bill surface area, corrected for body size (wing length), for each species. Figure S3 The correlation between rainfall and humidity. Humidity is mean summer water vapour pressure ( $\mathrm{hPa}$ ) and rainfall is mean summer rainfall $(\mathrm{mm})$ averaged for the preceding 5 summers prior to capture; summer is defined as the months December to February. Figure S4 Relationship between mean maximum summer temperature and mean summer humidity. Humidity is mean summer water vapour pressure ( $\mathrm{hPa}$ ) and temperature is mean summer temperature $\left({ }^{\circ} \mathrm{C}\right)$ averaged for the preceding 5 summers prior to capture; summer is defined as the months December to February. (DOCX 3198 kb)

\section{Acknowledgements}

We thank Jesse Smith for undertaking all the measuring and museum staff at the Australian National Wildlife Collection (CSIRO), Museum Victoria, and the Australian Museum for access to specimens. Peter Marsack provided useful discussion and insightful comments on the manuscript.

\section{Funding}

This work is funded by a grant from the Centre for Biodiversity Analysis, a joint initiative between ANU and CSIRO. JG was partially supported by an ARC Future Fellowship (FT150100139). LK was supported by an ARC Future Fellowship (FT110100453).

\section{Availability of data and material}

Please contact author for data requests.

\section{Authors' contributions}

$J G$ and MRES conceived the study. JG, L, KI, JS collected the data and LK and JG designed the analysis. LK analysed the data. JG wrote the manuscript and LK and MRES assisted with interpretation of results and all authors contributed manuscript feedback. All authors read and approved the final manuscript.

\section{Competing interests}

The authors declare that they have no competing interests.

\section{Consent for publication}

Not applicable.

\section{Ethics approval and consent to participate}

Not applicable for work with museum specimens.

\section{Author details}

${ }^{1}$ Division of Evolution, Ecology and Genetics, The Australian National University, Canberra, ACT 0200, Australia. ${ }^{2}$ Centre for Integrative Ecology, School of Life and Environmental Sciences, Deakin University, Burwood, VIC 3125, Australia. ${ }^{3}$ Australian National Wildlife Collection, National Research Collections Australia, CSIRO GPO Box 1700, Canberra, ACT 2601, Australia. ${ }^{4}$ The Fenner School of Environment and Society, The Australian National University, Canberra, ACT 0200, Australia.

Received: 3 August 2016 Accepted: 22 November 2016

Published online: 07 December 2016

\section{References}

1. Scholander PF. Evolution of climatic adaptation in homeotherms. Evolution. 1955:9:15-26.

2. Dawson WR. Evaporative losses of water by birds. Comp Biochem Phys A. 1982;71:495-509.

3. Bergmann C. Uber die verhaltnisse der warmeokonomie der thiere zu ihrer grosse. Gottinger Studien. 1847;3:595-708.

4. Willson MF, Karr JR, Roth RR. Ecological aspects of avian bill-size variation. Ecology. 1975;87(1):32-44.

5. Grant PR, Grant BR. Unpredictable evolution in a 30-year study of Darwin's finches. Science. 2002;296:707-11

6. Tattersall GJ, Andrade DV, Abe AS. Heat exchange from the toucan bill reveals a controllable vascular thermal radiator. Science. 2009;325:468-70.

7. Symonds MRE, Tattersall GJ. Geographical variation in bill size across bird species provides evidence for Allen's rule. Am Nat. 2010;176:188-97.

8. Tattersall GJ, Arnaout B, Symonds MRE. The evolution of the avian bill as a thermoregulatory organ. Biol Rev. 2016. doi:10.1111/brv.12299.

9. van de Ven TMFN, Martin RO, Vink TJF, McKechnie AE, Cunningham SJ. Regulation of heat exchange across the hornbill beak: functional similarities with toucans? PLoS One. 2016;11(5):e0154768.

10. Hagan AA, Heath JE. Regulation of heat loss in the duck by vasomotion in the bill. J Therm Biol. 1980;5:95-101.

11. Luther D, Greenberg R. Habitat type and ambient temperature contribute to bill morphology. Ecol Evol. 2014;4:699-705.

12. Greenberg R, Cadena V, Danner RM, Tattersall GJ. Heat loss may explain bill size differences between birds occupying different habitats. PLoS ONE. 2012;7:e40933.

13. Allen JA. The influence of physical conditions in the genesis of species. Radic Rev. 1877;1:108-40.

14. Greenberg R, Danner RM. The influence of the California marine layer on bill size in a generalist songbird. Evolution. 2012;66:3825-35.

15. Bartholomew GA, Cade TJ. The water economy of land birds. Auk. 1963; 80:504-39. 
16. Scholander PF, Hock R, Walters V, Johnson F, Irving L. Heat regulation in some arctic and tropical mammals and birds. Biol Bull. 1950;99:237-58.

17. James FC. Geographic size variation in birds and its relationship to climate. Ecology. 1970;51:365-90

18. Marder J, Arad Z. Panting and acid-base regulation in heat stressed birds. Comp Biochem Physiol A Physiol. 1989:94:395-400.

19. James FC. Complementary descriptive and experimental studies of clinal variation in birds. Am Zool. 1991;3:694-706.

20. Gerson AR, Krabbe Smith E, Smit B, McKechnie AE, Wolf BO. The impact of humidity on evaporative cooling in small desert birds exposed to high air temperatures. Physiol Biochem Zool. 2014;87(6):782-95.

21. Campbell-Tennant DJE, Gardner JL, Kearney MR, Symonds MRE. Climaterelated variation, and evidence for increases in bill size over the past century in Australian parrot species. J Biogeogr. 2015;42:1163-75.

22. Gardner JL, Trueman JWH, Ebert D, Joseph L, Magrath RD. Phylogeny and evolution of the Meliphagoidea, the largest radiation of Australasian songbirds. Mol Phylogenet Evol. 2010;55:1087-102.

23. Joseph L, Toon A, Nyari AS, Longmore NW, Rowe KMC, Haryoko T, Trueman J, Gardner JL. A new synthesis of the molecular systematics and biogeography of honeyeaters (Passeriformes: Meliphagidae) highlights biogeographical complexity of a spectacular avian radiation. Zool Scripta. 2014;43:235-48.

24. Summers RW. The value of bill lengths of museum specimens in biometric studies. Wader Study Group Bulletin. 1976;17:10-1.

25. Gosler AG, Greenwood JJD, Baker JK, Davidson NC. The field determination of body size and condition in passerines: a report to the British Ringing Committee. Bird Study. 1998;45:92-103.

26. Gardner JL, Amano T, Mackey BG, Sutherland WJ, Clayton M, Peters A. Dynamic size responses to climate change: prevailing effects of rising temperature drive long-term body size increases in a semi-arid passerine. Glob Change Biol. 2014;20:2062-75.

27. Hutchinson M, Kesteven J, Xu T. ANUClimate 1.0, 0.01 degree, Australian Coverage, 1970-2014. Canberra: Australian National University; 2014.

28. Greenberg R, Etterson M, Danner RM. Seasonal dimorphism in the horny bills of sparrows. Ecol Evol. 2013;3:389-98.

29. Butler DG, Cullis BR, Gilmour AR, Gogel BJ. ASReml-R reference manual, release 3. 2009. Technical report, Queensland Department of Primary Industries.

30. Jetz W, Thomas GH, Joy JB, Hartmann K, Mooers AO. The global diversity of birds in space and time. Nature. 2012;491:444-8.

31. Hackett SJ, Kimball RT, Reddy S, Bowie RCK, Braun EL, et al. A phylogenomic study of birds reveals their evolutionary history. Science. 2008:320:1763-8.

32. Paradis E, Claude J, Strimmer K. APE: analyses of phylogenetics and evolution in R language. Bioinformatics. 2004;20:289-90.

33. Hadfield JD, Nakagawa S. General quantitative genetic methods for comparative biology: phylogenies, taxonomies and multi-trait models for continuous and categorical characters. J Evol Biol. 2010;23:494-508.

34. Hadfield JD. MCMC methods for multi-response generalized linear mixed models: the MCMCglmm R Package. J Stat Softw. 2010;33:1-22.

35. Hadfield JD, Krasnov BR, Poulin R, Nakagawa S. A tale of two phylogenies: comparative analyses of ecological interactions. Am Nat. 2014;183:174-87.

36. Nussey DH, Wilson AJ, Brommer JE. The evolutionary ecology of individual phenotypic plasticity in wild populations. J Evol Biol. 2007;20:831-44.

37. Powers DR. Effect of temperature and humidity on evaporative water loss in Anna's hummingbird (Calypte anna). J Comp Physiol B. 1992;162:74-84.

38. Calder WA, King JR. Thermal and caloric relations of birds. In: Farner DS, King JR, editors. Avian biology, vol IV. New York: Academic; 1974. p. 259-413.

39. Sherwood SC, Huber M. An adaptability limit to climate change due to heat stress. Proc Natl Acad Sci USA. 2010;107:9552-5.

40. Dillon ME, Wang G, Huey RB. Global metabolic impacts of recent climate warming. Nature. 2010;467:70-706.

41. Janzen $\mathrm{DH}$. Why mountain passes are higher in the tropics. Am Nat. 1967; 101:233-49.

42. Şekercioğlu CH, Primack RB, Wormworth J. The effects of climate change on birds. Biol Conserv. 2012;148(1):1-18.

43. Tewksbury JJ, Huey RB, Deutsch CA. Putting the heat on tropical animals. Science. 2008;320:1296-7.

44. Cooper N, Freckleton RP, Jetz W. Phylogenetic conservatism of environmental niches in mammals. Proc R Soc B Biol Sci. 2011:278:2384-91.

45. Khaliq I, Hof C, Prinzinger R, Bohning-Gaese K, Pfenninger M. Global variation in thermal tolerances and vulnerability of endotherms to climate change. Proc R Soc B Biol Sci. 2014;281(1789):20141097.
46. Lovegrove BG, Canale C, Levesque D, Fluch G, Řeháková-Petrů M, Ruf T. Are tropical small mammals physiologically vulnerable to Arrhenius effects and climate change? Physiol Biochem Zool. 2014;87(1):30-45.

47. McKecknie AE, Wolf BO. Climate change increases the likelihood of catastrophic avian mortality events during extreme heat waves. Biol Lett. 2010;6:253-6.

48. Speakman JR, Król E. Maximal heat dissipation capacity and hyperthermia risk: neglected key factors in the ecology of endotherms. J Anim Ecol. 2010;79:726-46

49. Huey RB, Kearney MR, Krockenberger A, Holtum JAM, Jess M, Williams SE. Predicting organismal vulnerability to climate warming: roles of behaviour, physiology and adaptation. Philos Trans R Soc Lond B Biol Sci. 2012;367: 1665-79.

50. Danner RM, Greenberg R. A critical season approach to Allen's rule: bill size declines with winter temperature in a cold temperate environment. J Biogeogr. 2014;42:114-20.

51. Lord J, Egan J, Clifford T, Jurado E, Leishman M, Williams D, Westoby M. Larger seeds in tropical floras: consistent patterns independent of growth form and dispersal mode. J Biogeogr. 1997;24:205-11.

52. Symonds MRE, Johnson CN. Determinants of local abundance in a major radiation of Australian passerines (Aves: Meliphagoidea). J Biogeogr. 2006:33:794-802.

\section{Submit your next manuscript to BioMed Central and we will help you at every step:}

- We accept pre-submission inquiries

- Our selector tool helps you to find the most relevant journal

- We provide round the clock customer support

- Convenient online submission

- Thorough peer review

- Inclusion in PubMed and all major indexing services

- Maximum visibility for your research

Submit your manuscript at www.biomedcentral.com/submit
C) Biomed Central 